From the University of Texas M. D. Anderson Cancer Center, Houston, TX; Puget Sound Cancer Consortium, Swedish Cancer Institute; Southwest Oncology Group Statistical Center, Seattle, WA University of Colorado Health Sciences Center, Denver, CO; University of Toronto, Toronto, Canada; Vanderbilt University Medical Center, Nashville, TN; and University of California, Davis, Cancer Center, Sacramento, CA.

†Deceased.

Submitted September 15, 2009 accepted December 22, 2009 published online ahead of print at www.jco.org on March 15, 2010.

Supported in part by PHS Cooperative Agreement Grants No. CA32102, CA38926, CA20319, CA46441, CA105409, CA42777, CA35192, CA46113, CA37981, CA76429, CA45377, CA12644, CA76447, CA46282, CA22433, CA58861 CA35261, CA58348, CA14028, CA74647, CA86780, CA04919, CA35090, CA35178, CA58416 CA58658, CA67575, CA63844, CA35119, CA35431, CA67663, and CA46136 from the National Cancer Institute; and by Bristol-Myers Squibb.

Presented in part at the 41 st Annual Meeting of the American Society of Clincal Oncology, May 13-17, 2005, Orlando, FL: the 43rd Annual Meeting of the American Society of Clinical Oncology, June 1-5, 2007, Chicago, IL; the 11th World Conference on Lung Cancer, International Association for the Study of Lung Cancer, July 3-6, 2005, Barcelona, Spain; and the 13th World Conference on Lung Cancer, International Association for the Study of Lung Cancer, July 31-August 4, 2009, San Francisco, CA

Authors' disclosures of potential conflicts of interest and author contributions are found at the end of this article.

Clinical Trials repository link available on JCO.org.

Corresponding author: Katherine M.W Pisters, MD, The University of Texas M. D. Anderson Cancer Center, PO Box 301402, Unit 432, Houston, TX 77230 1402; e-mail: kpisters@mdanderson.org (C) 2010 by American Society of Clinical Oncology

$0732-183 \times / 10 / 2811-1843 / \$ 20.00$

DOI: $10.1200 / J C O .2009 .26 .1685$

\title{
Surgery With or Without Preoperative Paclitaxel and Carboplatin in Early-Stage Non-Small-Cell Lung Cancer: Southwest Oncology Group Trial S9900, an Intergroup, Randomized, Phase III Trial
}

Katherine M.W. Pisters, Eric Vallières, John J. Crowley, Wilbur A. Franklin, Paul A. Bunn Jr, Robert J. Ginsberg†, Joe B. Putnam Jr, Kari Chansky, and David Gandara

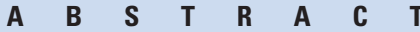

\section{Purpose}

Patients with early-stage non-small-cell lung cancer (NSCLC) have a poor prognosis even after complete resection. Earlier studies of preoperative (induction) chemotherapy in resectable NSCLC demonstrated feasibility and encouraging survival data. This randomized phase III trial compared overall survival (OS) for preoperative paclitaxel and carboplatin followed by surgery with surgery alone in patients with early-stage NSCLC.

\section{Patients and Methods}

Patients with clinical stage IB-IIIA NSCLC (excluding superior sulcus tumors and N2 disease) were eligible. Patients were randomly assigned to surgery alone or to three cycles of paclitaxel (225 $\mathrm{mg} / \mathrm{m}^{2}$ ) and carboplatin (area under curve, 6) followed by surgical resection. The primary end point was OS; secondary end points were progression-free survival (PFS), chemotherapy response, and toxicity

\section{Results}

The trial closed early with 354 patients after reports of a survival benefit for postoperative chemotherapy in other studies. The median OS was 41 months in the surgery-only arm and 62 months in the preoperative chemotherapy arm (hazard ratio, $0.79 ; 95 \% \mathrm{Cl}, 0.60$ to $1.06 ; P=.11$.) The median PFS was 20 months for surgery alone and 33 months for preoperative chemotherapy (hazard ratio, $0.80 ; 95 \% \mathrm{Cl}, 0.61$ to $1.04 ; P=.10$.) Major response to chemotherapy was seen in $41 \%$ of patients; no unexpected toxicity was observed.

\section{Conclusion}

This trial closed prematurely after compelling evidence supporting postoperative chemotherapy emerged. Although OS and PFS were higher with preoperative chemotherapy, the differences did not reach statistical significance. At present, stronger evidence exists for postoperative chemotherapy in early-stage NSCLC

\section{J Clin Oncol 28:1843-1849. (C) 2010 by American Society of Clinical Oncology}

\section{INTRODUCTION}

Lung cancer remains the most common cause of cancer-related death in men and women. Nonsmall-cell lung cancer (NSCLC) is the most common type, and it accounts for $85 \%$ of cases. Unfortunately, the majority of patients with NSCLC have metastatic disease at diagnosis. However, even patients with resectable disease have poor survival.

The need to improve survival rates in these patients prompted research exploring the role of systemic therapy in operable NSCLC. In the 1990s, several clinical trials of preoperative chemotherapy (also known as induction chemotherapy) followed by surgery or radiation in patients with locally advanced NSCLC showed improvements in survival. $^{1-6}$ A phase II trial of preoperative paclitaxel and carboplatin chemotherapy established feasibility and safety with encouraging overall survival (OS) results in patients with early-stage NSCLC. ${ }^{7,8}$ These findings prompted this phase III trial of preoperative paclitaxel and carboplatin plus surgery or surgery alone in early-stage NSCLC.

\section{PATIENTS AND METHODS}

\section{Study Design}

This intergroup, randomized, phase III trial (S9900) compared three cycles of preoperative paclitaxel and carboplatin followed by surgery with surgery alone in patients 
with clinical stage IB, II, or selected IIIA (excluding superior sulcus tumors and ipsilateral mediastinal lymph node involvement) NSCLC. The main objective was to compare OS. Secondary objectives were to compare progression-free survival (PFS), relapse patterns, operative morbidity and mortality, and chemotherapy response and toxicities. The protocol was approved by the institutional review boards at the participating institutions; all patients provided written informed consent. Data were collected, managed, and analyzed by the Southwest Oncology Group (SWOG) Data Operations Center at Cancer Research and Biostatistics. The SWOG Data and Safety Monitoring Committee oversaw the conduct of the study.

\section{Eligibility Criteria}

To be eligible for the trial, patients had to be $\geq 18$ years old and have clinical stage T2N0, T1-2N1, or T3N0-1 NSCLC (based on cytology or pathology), as defined by history, physical examination, laboratory evaluation, chest computed tomography (CT), and bronchoscopy. Mediastinoscopy or biopsy (to rule out involvement) was required for adenopathy larger than $1.0 \mathrm{~cm}$ on $\mathrm{CT}$. Clinical $\mathrm{T}$ stage was defined by $\mathrm{CT}$ findings. Clinical $\mathrm{N}$ stage was defined by mediastinoscopy and CT findings. N1 nodes were considered clinically involved if larger than $1.0 \mathrm{~cm}$ on CT. Patients were also required to have a Zubrod performance status of 0 or 1 ; adequate hematologic, renal, and hepatic function for chemotherapy and surgery; a predicted postresection forced expiratory volume in 1 second of $\geq 1.0 \mathrm{~L}$; and measurable disease by RECIST (Response Evaluation Criteria in Solid Tumors). ${ }^{9}$

\section{Pretreatment Evaluation}

All patients underwent chest CT, chest x-ray, electrocardiography, pulmonary function tests, bronchoscopy, mediastinoscopy (when required by protocol), and laboratory tests. As it was not universally available at study initiation, positron emission tomography imaging was optional. Brain and bone imaging were performed if indicated.

\section{Treatment Plan}

After providing informed consent, patients were randomly assigned to either surgery alone (arm 1) or preoperative chemotherapy followed by surgery (arm 2). The randomization was stratified on clinical stage (IB/IIA $v$ IIB/IIIA) using a dynamic balancing algorithm.

Surgery alone. Patients in arm 1 underwent surgery within 14 days after trial registration. Segmentectomy and wedge resection were discouraged, and a complete mediastinal lymph node dissection/sampling was recommended.

Preoperative chemotherapy plus surgery. Patients in arm 2 received paclitaxel $\left(225 \mathrm{mg} / \mathrm{m}^{2}\right.$ given intravenously over 3 hours) and carboplatin (area under the curve of 6 given intravenously over 30 minutes after paclitaxel) every 21 days for three cycles. Before cycles 2 and 3, patients had a history, blood tests, and chest $\mathrm{x}$-ray. Toxicities were graded using National Cancer Institute Common Toxicity Criteria, version 2.0. Chemotherapy was modified for toxicity as necessary. Within 2 to 6 weeks after cycle 3 of chemotherapy, patients were re-evaluated for surgery by a history, physical examination, chest CT, chest $\mathrm{x}$-ray, electrocardiography, pulmonary function tests, and laboratory tests. Radiographic response was assessed using RECIST. ${ }^{9}$ Surgery occurred within 3 to 8 weeks after chemotherapy.

Follow-up. Patients were removed from protocol-based therapy and treated per their physicians if they had incomplete resection; N2, N3, T4, or M1 disease at surgery; or unacceptable toxicity. All patients were observed for recurrence, long-term toxicities, and survival. After protocol therapy was completed, follow-up visits, which included a history and chest imaging, were scheduled every 3 months for 1 year, every 6 months for the next 4 years, and then annually.

Statistical considerations. The primary objective was to compare OS between the two study arms (intent-to-treat analysis). The study was designed to detect a $33 \%$ increase in median OS (over an expected 2.7 years) with $81 \%$ power, using a one-sided .025 significance level, with an accrual goal of 300 patients per arm. OS was defined as the time between registration and death. PFS was defined as the time between registration and disease progression (defined radiographically before or after surgery or at surgery if more extensive disease) or death, whichever occurred first.

Estimates of median and survival rates were calculated by the KaplanMeier method. Survival comparisons were made using Cox proportional hazards models, stratified by stage (IB/IIA $v$ IIB/IIIA). Risk estimates for local and distant relapse were generated using cumulative incidence analyses with competing risk designation for death or disease progression to other sites.

The SWOG Data and Safety Monitoring Committee recommended early closure of the S9900 trial (S9900 closed July 1, 2004) after reports of an OS benefit from postoperative chemotherapy in patients with resected NSCLC. ${ }^{10-12}$

\section{RESULTS}

\section{Patient Characteristics}

Between October 1999 and June 2004, 354 patients were accrued. Seventeen patients were ineligible for the following reasons: surgery alone, incorrect stage (seven patients), no measurable disease $(\mathrm{n}=3)$, and incorrect histology $(\mathrm{n}=1)$; chemotherapy and surgery, missing required baseline bronchoscopy $(n=3)$, incorrect histology $(n=2)$, and incorrect stage $(n=1)$. Among eligible patients, 168 were randomly assigned to arm 1 (surgery alone) and 169 to arm 2 (preoperative chemotherapy and surgery; Fig 1). Baseline patient characteristics are summarized in Table 1. Known prognostic variables were well balanced between the two study arms.

\section{Chemotherapy Compliance, Response, and Toxicity}

Seventy-nine percent of patients assigned to receive chemotherapy completed all three planned cycles. Reasons for not completing chemotherapy included adverse effects (8\%), refusal (3\%), disease progression (2\%), and death (2\%). Chemotherapy response rates are presented in Appendix Table A1 (online only). The overall major response (complete or partial response) rate was $41 \%$. Sixteen patients were not assessable for radiographic response because of improper or inadequate follow-up imaging $(n=8)$; chemotherapy refusal $(n=5)$; early chemotherapy discontinuation $(n=2)$; or delinquent data submission $(\mathrm{n}=1)$.

Appendix Table A2 (online only) summarizes chemotherapy toxicities. Five patients were not assessable for toxicity (refused chemotherapy after random assignment); therefore, toxicity data were available for 164 patients. Grade 3 or 4 neutropenia occurred in 48\%, but only $4 \%$ had febrile neutropenia. Grade 3 or 4 paclitaxel-induced hypersensitivity reactions occurred in 3\%. Anemia and thrombocytopenia were uncommon. Fifty-one percent of patients had grade 1 or 2 fatigue or malaise, while only $4 \%$ experienced grade 3 fatigue.

There were three deaths during preoperative chemotherapy. One patient died at home from unknown causes on day 8 of cycle 1; one died on day 9 of cycle 2 from complications of a stroke, pneumonia, and neutropenia; and one died from congestive heart failure 51 days after cycle 2 .

\section{Surgery}

One hundred sixty-five of 168 patients in the surgery-alone group underwent surgical exploration (Table 2), two refused surgery and one could not be intubated and did not have surgery. One hundred forty-six patients had complete resection (R0; $88 \%$ of those who had exploration and $87 \%$ of those randomly assigned to surgery alone), seven had microscopic residual disease (R1), five had gross residual disease (R2), and seven underwent exploration without resection. Four patients refused their randomly assigned treatment and received preoperative chemotherapy (a major protocol violation). 


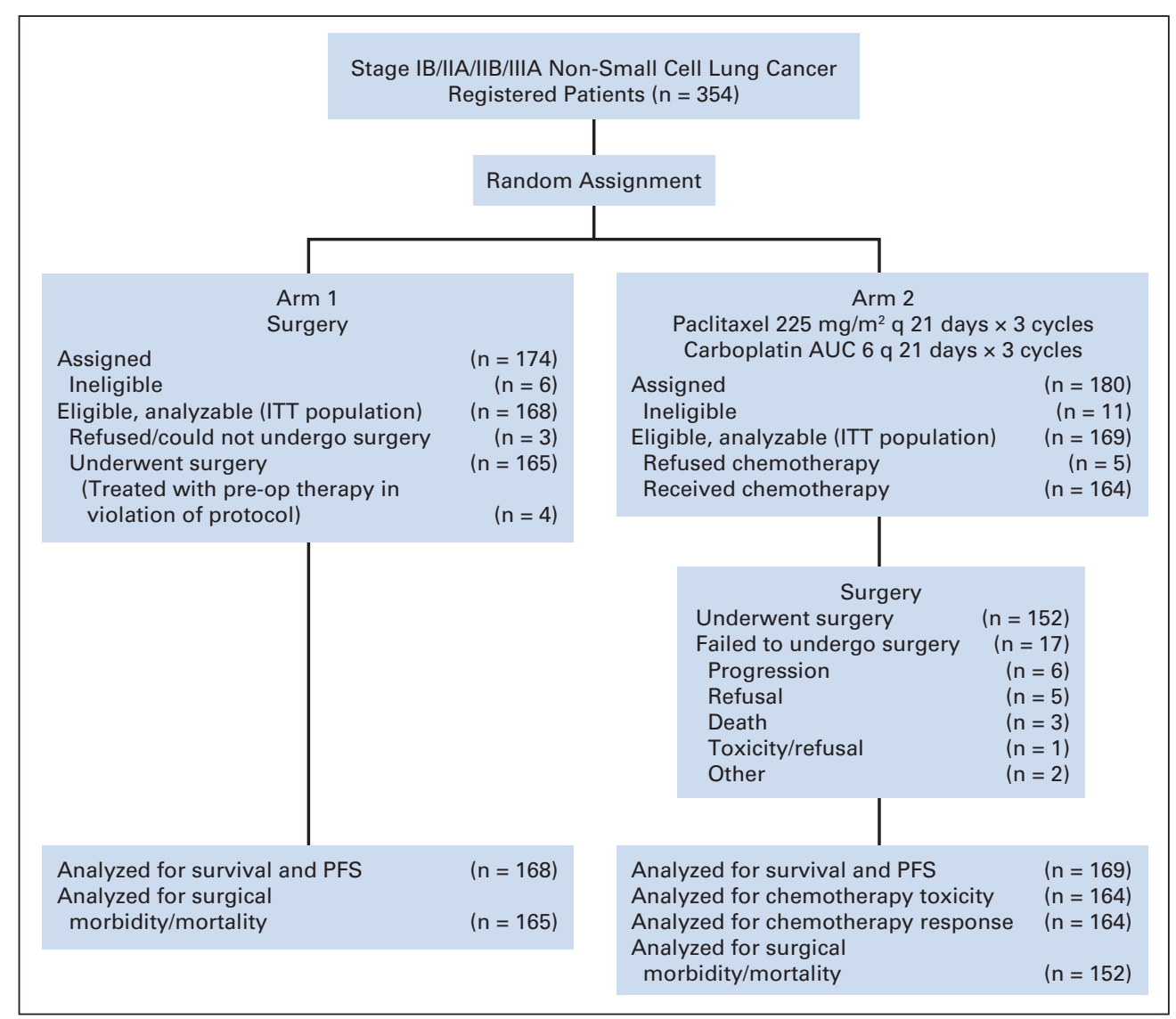

Fig 1. CONSORT diagram for 354 registered patients. AUC, area under curve; $q$ every; ITT, intention to treat; pre-op, preoperative; PFS, progression-free survival.

Among the 169 patients in the preoperative chemotherapy and surgery group, 152 underwent surgical exploration. Reasons for not undergoing surgery included disease progression $(n=6)$; patient refusal $(n=5)$; death during preoperative therapy $(n=3)$; toxicity/

\begin{tabular}{|c|c|c|}
\hline \multirow[b]{2}{*}{ Characteristic } & \multicolumn{2}{|r|}{$\%$} \\
\hline & $\begin{array}{l}\text { Surgery Alone } \\
\quad(\mathrm{n}=168)\end{array}$ & $\begin{array}{l}\text { Preoperative Chemotherapy } \\
\qquad(\mathrm{n}=169)\end{array}$ \\
\hline Median age, years & 64 & 65 \\
\hline Range & $35-82$ & $38-83$ \\
\hline \multicolumn{3}{|l|}{ Sex } \\
\hline Male & 68 & 64 \\
\hline Female & 32 & 36 \\
\hline \multicolumn{3}{|l|}{ Performance status } \\
\hline 0 & 63 & 66 \\
\hline 1 & 37 & 34 \\
\hline \multicolumn{3}{|l|}{ Clinical stage } \\
\hline $\mathrm{IB} / \mathrm{II}$ & 68 & 67 \\
\hline$\|B /\| A$ & 32 & 33 \\
\hline \multicolumn{3}{|l|}{ Histology } \\
\hline Squamous cell carcinoma & 42 & 34 \\
\hline Adenocarcinoma & 33 & 31 \\
\hline NSCLC, other* & 23 & 29 \\
\hline Large cell carcinoma & 2 & 6 \\
\hline
\end{tabular}

refusal $(\mathrm{n}=1)$; and other $(\mathrm{n}=2)$. One hundred forty-two patients had complete resection (R0; $93 \%$ of those who underwent exploration and $84 \%$ of those randomly assigned to arm 2), five had microscopic residual disease (R1), and five underwent exploration without resection. One patient who underwent $\mathrm{R} 1$ resection had refused preoperative chemotherapy and proceeded directly to surgery (major protocol

\begin{tabular}{|c|c|c|c|c|}
\hline \multirow[b]{2}{*}{ Surgery } & \multicolumn{2}{|c|}{$\begin{array}{l}\text { Surgery Alone } \\
\qquad(\mathrm{n}=168)\end{array}$} & \multicolumn{2}{|c|}{$\begin{array}{c}\text { Preoperative } \\
\text { Chemotherapy } \\
(n=169)\end{array}$} \\
\hline & $\begin{array}{c}\text { Total } \\
\text { Explored }\end{array}$ & Ro & $\begin{array}{c}\text { Total } \\
\text { Explored }\end{array}$ & R0 \\
\hline All procedures & 165 & $146^{*}$ & 152 & $142 \dagger$ \\
\hline Pneumonectomy & 26 & 24 & 24 & 21 \\
\hline Lobectomy & 117 & 111 & 109 & 107 \\
\hline Bilobectomy & 11 & 10 & 10 & 10 \\
\hline Wedge resection/segmentectomy & 4 & 1 & 1 & 1 \\
\hline Resected, procedure not reported & 0 & 0 & 3 & 3 \\
\hline Exploration, no resection & 7 & 0 & 5 & 0 \\
\hline \multicolumn{5}{|c|}{$\begin{array}{l}\text { NOTE. Data are No. of patients, by intent to treat. } \\
\text { *Represents } 88 \% \text { of those who had exploration and } 87 \% \text { of those assigned } \\
\text { to arm. Four of the completely resected (R0) patients had refused assigned } \\
\text { arm and received preoperative chemotherapy (a major protocol violation). One } \\
\text { patient who did not receive surgery had also refused assigned arm and } \\
\text { received chemotherapy. } \\
\text { tRepresents } 93 \% \text { of those who had exploration and } 84 \% \text { of those assigned } \\
\text { to arm. One patient assigned to preoperative chemotherapy refused assigned } \\
\text { arm and received surgery only, with microscopic residual disease (R1). }\end{array}$} \\
\hline
\end{tabular}




\begin{tabular}{|c|c|c|c|c|}
\hline \multirow[b]{2}{*}{ Parameter } & \multicolumn{2}{|c|}{$\begin{array}{c}\text { Surgery } \\
\text { Alone } \\
(\mathrm{n}=165)\end{array}$} & \multicolumn{2}{|c|}{$\begin{array}{l}\text { Preoperative } \\
\text { Chemotherapy } \\
(n=152)\end{array}$} \\
\hline & No. & $\%$ & No. & $\%$ \\
\hline \multicolumn{5}{|l|}{ Operative morbidity } \\
\hline Pneumonia & 12 & 7 & 10 & 7 \\
\hline Reintubation & 9 & 5 & 11 & 7 \\
\hline Tracheostomy & 3 & 2 & 2 & 1 \\
\hline ICU readmission & 10 & 6 & 8 & 5 \\
\hline Chest tube air leak & 12 & 7 & 13 & 9 \\
\hline Respiratory failure & 7 & 4 & 10 & 7 \\
\hline Atrial arrhythmia & 27 & 16 & 24 & 16 \\
\hline \multicolumn{5}{|c|}{ Postoperative mortality, by type of surgery } \\
\hline Lobectomy & $3 / 117$ & 3 & $3 / 109$ & 3 \\
\hline Wedge resection & $1 / 4$ & 25 & $0 / 1$ & 0 \\
\hline Pneumonectomy & $0 / 26$ & 0 & $4 / 24$ & 17 \\
\hline Total & $4 / 147$ & 3 & $7 / 134$ & 5 \\
\hline
\end{tabular}

NOTE. Data are for patients who had a complication or died. Abbreviation: ICU, intensive care unit.

violation). Fifteen (9\%) of 169 patients randomly assigned to arm 2 were found to have pathologic complete response (no viable tumor in the resected specimen). This included two patients (of five) who had radiographic complete response, 10 with radiographic partial response and three with stable disease.

Table 2 presents surgical results by randomization arm. The surgical procedures performed did not differ significantly between the arms. The complete resection (R0) rates were also similar in the two groups. After exclusion of the five patients with major protocol violations, $87 \%$ of surgery-alone patients had complete resection versus $84 \%$ of those who received preoperative chemotherapy.

Surgical morbidity and mortality data are summarized in Table 3. There were 11 deaths after surgery. Four occurred in arm 1:3 after lobectomy and one after a wedge/chest wall resection. Causes of death were hemorrhage (postoperative day 4), sudden death (postoperative day 5), pneumonia (postoperative day 20), and multiple complications (postoperative day 5). Seven postoperative deaths occurred in arm 2: four after pneumonectomy (two right sided and two left sided) and three after lobectomy. Causes of death in the pneumonectomy patients were multiorgan failure (postoperative day 13), pneumonia/ acute respiratory distress syndrome (ARDS; postoperative day 27), sudden death (postoperative day 30), and aspiration/ARDS/multiorgan failure (postoperative day 52); causes of death in the lobectomy patients were sudden death (postoperative day 9), sepsis/atrial fibrillation/multiorgan failure (postoperative day 15), and hemoptysis (postoperative day 15).

\section{Survival}

PFS. As of September 3, 2008, with a median follow-up of 64 months, PFS rates at 1,3 , and 5 years were $68 \%, 38 \%$, and $33 \%$ in the surgery-alone group (arm 1) and $68 \%, 48 \%$, and $42 \%$ in the preoperative chemotherapy and surgery group ( $\operatorname{arm} 2$; Fig 2). The median PFS was 20 months in arm 1 (95\% CI, 17 to 28 months) and 33 months in arm 2 (95\% CI, 21 to 48 months; hazard ratio [HR], $0.80 ; 95 \%$ CI, 0.61 to $1.04 ; P=.10)$.

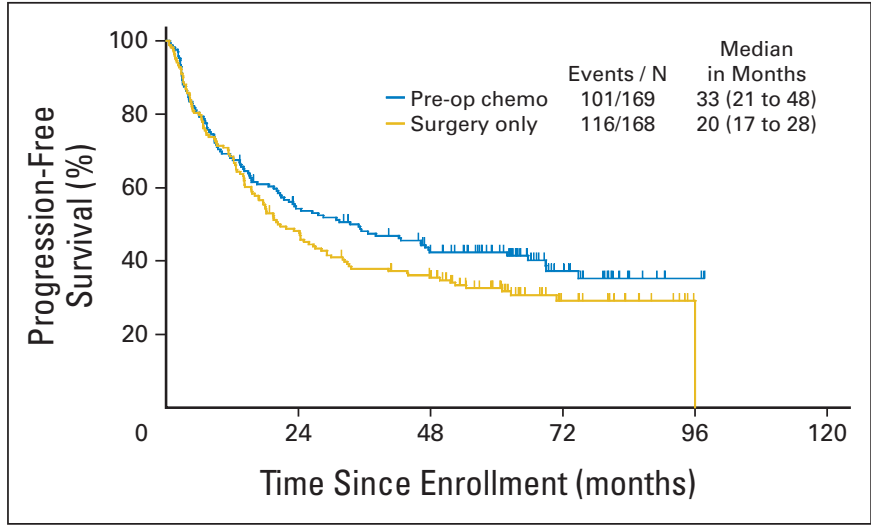

Fig 2. Progression-free survival by treatment arm (median follow-up, 64 months). Pre-op, preoperative; chemo, chemotherapy; N, number.

Sites of first relapse are shown in Appendix Table A3 (online only). After exclusion of the 10 patients whose first relapse site was unknown, the estimated probabilities (by cumulative incidence analysis) of any distant recurrence at 12 and 24 months were $18 \%$ and $30 \%$ for arm 1 and $15 \%$ and $24 \%$ for arm 2, respectively. There were no significant differences in patterns of distant recurrence between the study arms. The risks of local-only recurrence at 12 and 24 months were $6 \%$ and $11 \%$ in arm 1 and $9 \%$ and $13 \%$ in arm 2. Survival after recurrence was similar in the two arms, with a median survival after progression of 12 months in the surgery-alone arm and 9 months in the preoperative chemotherapy $\operatorname{arm}(P=.77 ; 2$-year postrelapse survival rates, $27 \%$ and $24 \%$, respectively).

OS. As of September 3, 2008, with a median follow-up of 64 months, OS rates at 1,3 , and 5 years were $79 \%, 56 \%$, and $41 \%$ in the surgery-alone arm and $82 \%, 61 \%$, and $50 \%$ in the preoperative chemotherapy plus surgery arm (Fig 3). The median OS was 41 months in arm 1 (95\% CI, 34 to 55 months) and 62 months in arm 2 (95\% CI, 40 to 76 months). The HR for preoperative chemotherapy plus surgery versus surgery only was 0.79 ( $95 \% \mathrm{CI}, 0.60$ to $1.06 ; P=.11$ ).

The influences of Zubrod performance status ( $0 v 1)$, stage (IB/ IIA $v$ IIB/IIIA), histology, and sex were examined with stepwise selection in a multivariate Cox regression model including treatment arm. Only stage (HR, 1.43; 95\% CI, 1.05 to 1.96; $P=.025$ in favor of lower stage) and sex (HR, 1.69; 95\% CI, 1.20 to $2.38 ; P=.003$ in favor of

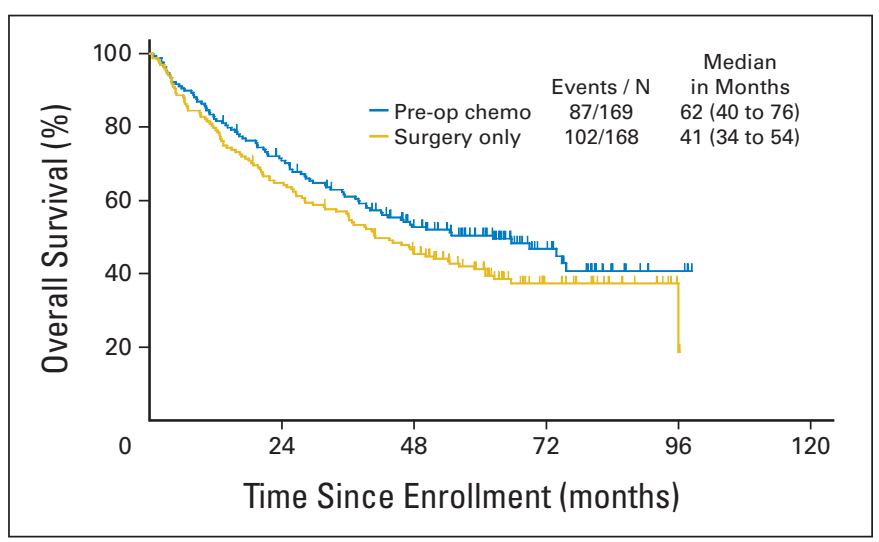

Fig 3. Overall survival by treatment arm (median follow-up, 64 months). Pre-op, preoperative; chemo, chemotherapy; $\mathrm{N}$, number. 
females) were found to be significantly prognostic for OS. Interactions between treatment arm and stage and between treatment arm and sex were not identified. The majority of patients enrolled were white (86\%), and the remaining were African American (7\%), Asian (<1\%), Native American $(<1 \%)$, or not reported (5\%). This ethnic distribution precluded any meaningful analysis of treatment effect by ethnicity.

\section{DISCUSSION}

This prospective randomized trial found trends in favor of the use of preoperative chemotherapy followed by surgery versus surgery alone in early-stage NSCLC; however, the differences did not reach statistical significance. The absolute improvement in OS rate at 5 years was 9\%, comparable with or better than differences observed with postoperative chemotherapy in operable NSCLC. ${ }^{10,11,13,14}$ This trial did not accrue its planned sample size because during its conduct, studies of postoperative chemotherapy found an OS benefit, establishing a new standard of care for resectable NSCLC.

The first reported phase III trial of preoperative chemotherapy for early-stage NSCLC was a French study ${ }^{15}$ that found chemotherapy led to an 11-month increase in median OS (37 v 26 months) and an $8.6 \%$ absolute increase in 4-year survival, but the differences were not statistically significant. With additional follow-up, the 3- and 5-year survival increases were stable at around 10\% $(P=.04$ at 3 years; $P=.06$ at 5 years), and statistically significant benefits from preoperative chemotherapy in the N0/N1 subgroup were confirmed (5-year OS rate, $49 \%$ v 34\%; $P=.02){ }^{16}$

A Scandinavian randomized trial ${ }^{17}$ of preoperative chemotherapy in early-stage NSCLC closed prematurely after slow accrual (90 patients in 6 years). The median and 5-year OS rates were 34 months and 36\% for preoperative chemotherapy versus 23 months and $24 \%$ for surgery alone (differences not significant). A large United King- dom trial found no difference in extent of surgical procedures performed, operative morbidity and mortality, or survival between patients randomly assigned to preoperative chemotherapy versus surgery alone (HR, $1.02 ; 95 \% \mathrm{CI}, 0.8$ to 1.31$).^{18}$

The Chemotherapy in Early stages NSCLC Trial (ChEST) was unique among randomized trials of preoperative chemotherapy as its primary end point was PFS. Similar to the $\$ 9900$ trial, ChEST closed early after accruing 270 of 700 planned patients. The median PFS and 3-year PFS rate were 2.9 years and $48 \%$ for surgery alone versus 4.0 years and $53 \%$ for preoperative chemotherapy and surgery $(P=.109$; $\mathrm{HR}, 0.71 ; 95 \% \mathrm{CI}, 0.50$ to $0.99 ; P=.011)$. OS results also favored preoperative chemotherapy. However, subset analyses found these benefits restricted to the stage IIB/IIIA patients. ${ }^{19}$ The ChEST findings were not consistent with the $\$ 9900$ subset analysis, in which no treatment arm and stage interaction was found, or the French trial, ${ }^{15}$ in which the N0/N1 patients experienced a greater benefit from chemotherapy. To our knowledge, the ChEST trial is the only preoperative chemotherapy trial to date in which the pneumonectomy rate was lower in patients receiving preoperative therapy. In our trial, pneumonectomy rates were similar in the two treatment arms.

The three-arm NATCH (Neoadjuvant/Adjuvant Taxol/Carboplatin Hope) trial, which accrued 624 patients compared disease-free survival with surgery alone versus three cycles of preoperative or postoperative paclitaxel/carboplatin chemotherapy and surgery in early-stage NSCLC. ${ }^{20}$ Similar to our study, there were no differences in complete resection rates, surgical procedures, or operative mortality. At 51 months of follow-up, the disease-free survival tended to favor chemotherapy, with an HR of 0.92 for preoperative chemotherapy (95\% CI, 0.81 to $1.04 ; P=.18$ ) and an HRof0.96 forpostoperativechemotherapy (95\% CI, 0.75 to $1.22 ; P=.73) .^{20}$

Table $4^{1-4,15-20}$ summarizes the results of the previously reported phase III trials of preoperative chemotherapy for operable NSCLC.

\begin{tabular}{|c|c|c|c|c|c|c|c|}
\hline First Author & Stage & Regimen & $\begin{array}{l}\text { No. of } \\
\text { Patients }\end{array}$ & $\begin{array}{c}\text { Radiographic Response } \\
\text { Rate (\%) }\end{array}$ & $\begin{array}{c}\text { Complete Resection } \\
\text { Rate }(\%)\end{array}$ & $\begin{array}{l}\text { Median OS } \\
\text { (months) }\end{array}$ & $\begin{array}{l}5 \text {-Year } \\
\text { OS (\%) }\end{array}$ \\
\hline \multirow[t]{2}{*}{ Roth $^{1,2}$} & IIIA & CEP & 28 & 35 & 39 & 21 & 36 \\
\hline & & Surgery & 32 & - & 31 & 14 & 15 \\
\hline \multirow[t]{2}{*}{ Rosell $\|^{3,4}$} & IIIA & MIP & 30 & 60 & 77 & 22 & 17 \\
\hline & & Surgery & 30 & - & 90 & 10 & 0 \\
\hline \multirow[t]{2}{*}{ DePierre $^{15,16}$} & $\mid \mathrm{B}, \mathrm{II}, \mathrm{II} \mathrm{A}(+\mathrm{N} 2)$ & MIP & 179 & 64 & 92 & 37 & 41 \\
\hline & & Surgery & 176 & - & 86 & 26 & 32 \\
\hline \multirow[t]{2}{*}{ Sorensen ${ }^{17}$} & $\mid \mathrm{B}, \mathrm{II}, \mathrm{II} \mathrm{A}$ & $\mathrm{PacCb}$ & 44 & 46 & 79 & 34 & 36 \\
\hline & & Surgery & 46 & - & 70 & 23 & 24 \\
\hline \multirow[t]{2}{*}{ Gilligan $^{18}$} & I, II, III & Platin + & 258 & 49 & NR & 53 & 44 \\
\hline & & Surgery & 261 & - & NR & 54 & 45 \\
\hline \multirow[t]{2}{*}{ This study } & $\mid \mathrm{B}, \mathrm{II}, \mathrm{III}$ & $\mathrm{PacCb}$ & 169 & 41 & 84 & 62 & 50 \\
\hline & & Surgery & 167 & - & 87 & 41 & 41 \\
\hline \multirow[t]{2}{*}{ Scagliotti ${ }^{19}$} & $\mid \mathrm{B}, \mathrm{II}, \mathrm{IIA}$ & GP & 129 & 35 & NR & 58 & $67^{*}$ \\
\hline & & Surgery & 141 & - & NR & Unest & $60^{*}$ \\
\hline \multirow[t]{3}{*}{ Felip 20} & I, II, IIIA & Preop PacCb & 199 & 59 & 87 & 55 & 47 \\
\hline & & Surgery & 210 & - & 90 & 49 & 44 \\
\hline & & Postop PacCb & 210 & - & 90 & 50 & 46 \\
\hline
\end{tabular}

Abbreviations: OS, overall survival; CEP, cyclophosphamide, etoposide, and cisplatin; MIP, mitomycin, ifosfamide, cisplatin; PacCb, paclitaxel, carboplatin; Platin +, vinorelbine/cisplatin, gemcitabine/cisplatin, mitomycin/vinblastine/cisplatin, docetaxel/carboplatin, or mitomycin/ifosfamide/cisplatin; GP, gemcitabine, cisplatin;

Preop, preoperative; Postop, postoperative; NR, not reported; Unest, unestimated.

*Three-year progression-free survival rates. 
With the exception of the LU22 trial, ${ }^{18}$ all studies found survival trends in favor of preoperative chemotherapy; the benefits seen were comparable in magnitude to those achieved with postoperative chemotherapy. Two meta-analyses have also examined the efficacy of chemotherapy in resectable NSCLC. ${ }^{21,22}$ Both meta-analyses were based on data extracted from abstracts and manuscripts, a method considered inferior to meta-analyses of individual patient data; thus, the results should be interpreted with caution. ${ }^{23}$ Berghmans et $\mathrm{al}^{21}$ found an OS HR of 0.66 for preoperative chemotherapy ( $95 \%$ CI, 0.48 to 0.93 ) and an HR of 0.84 for postoperative chemotherapy ( $95 \%$ CI, 0.78 to 0.89 ). The Burdett et $\mathrm{al}^{22}$ meta-analysis found an OS HR of 0.82 (95\% CI, 0.69 to $0.97 ; P=.02$ ) with an absolute benefit of $6 \%$ at 5 years for preoperative chemotherapy in randomized trials.

A meta-analysis directly comparing the efficacy of postoperative versus preoperative chemotherapy for resectable NSCLC in randomized trials found an OS HR of 0.80 for postoperative chemotherapy (95\% CI, 0.73 to 0.87 ) and 0.81 for preoperative chemotherapy (95\% $\mathrm{CI}, 0.68$ to 0.97$)$. Using indirect comparison meta-analysis, the relative hazard of postoperative compared with preoperative chemotherapy was 0.99 (95\% CI, 0.81 to $1.21 ; P=.900)$. Findings were similar for disease-free survival. The authors concluded that postoperative and preoperative chemotherapy yielded similar survival benefits. ${ }^{24}$

Concerns have been raised that preoperative chemotherapy increases surgical morbidity and mortality. In this and other trials, surgical complication rates after preoperative chemotherapy were similar to rates observed after surgery alone. However, postoperative mortality rates were higher in patients who underwent pneumonectomy after preoperative therapy. ${ }^{25,26}$

Although the observed benefits of preoperative and postoperative chemotherapy in the reported phase III trials and meta-analysis appear similar, one must consider inherent differences as a consequence of modality sequencing. The delivery of preoperative chemotherapy is intended to increase the percentage of patients who receive systemic therapy without interfering with the percentage who receive surgery. In contrast, when surgery is the initial modality, estimates are that fewer than $75 \%$ of patients initially eligible for preoperative chemotherapy and surgery ultimately receive postoperative chemotherapy. In the NATCH trial, ${ }^{20} 90 \%$ of patients completed three cycles of chemotherapy in the preoperative chemotherapy arm, compared with $66 \%$ of patients in the postoperative chemotherapy arm. By increasing the percentage of patients who actually receive chemotherapy, the preoperative chemotherapy strategy may yield superior survival results. Unfortunately, a prospective, randomized, phase III trial addressing this question failed to accrue sufficient patients in the United States. Although a subset of patients may benefit from a preoperative strategy, this is not yet defined.

In conclusion, phase III trials of preoperative chemotherapy for operable NSCLC support its use with survival benefits comparable to those seen with postoperative chemotherapy. The $\$ 9900$ study found a $21 \%$ reduction in the risk of death and a 9\% improvement in 5-year OS rate with three cycles of preoperative paclitaxel and carboplatin, although these improvements were not statistically significant. Based on clinical trial data available at this time, stronger evidence exists supporting the use of postoperative chemotherapy in patients with resectable NSCLC.

\section{AUTHORS' DISCLOSURES OF POTENTIAL CONFLICTS} OF INTEREST

Although all authors completed the disclosure declaration, the following author(s) indicated a financial or other interest that is relevant to the subject matter under consideration in this article. Certain relationships marked with a " $U$ " are those for which no compensation was received; those relationships marked with a "C" were compensated. For a detailed description of the disclosure categories, or for more information about ASCO's conflict of interest policy, please refer to the Author Disclosure Declaration and the Disclosures of Potential Conflicts of Interest section in Information for Contributors.

Employment or Leadership Position: None Consultant or Advisory Role: Eric Vallières, Bristol-Myers Squibb (U); Paul A. Bunn Jr, AstraZeneca (C), ImClone Systems (C), Eli Lilly (C), GlaxoSmithKline (C), Amgen (C), Genentech (C), sanofi-aventis (C), Boehringer Ingelheim (C), Bristol-Myers Squibb (C), OSI Pharmaceuticals (C), Roche (C); David Gandara, Bristol-Myers Squibb (C), Genentech (C), AstraZeneca (U), sanofi-aventis (C), Bayer Pharmaceuticals (C), Response Genetics (U) Stock Ownership: None Honoraria: Eric Vallières, Bristol-Myers Squibb; Paul A. Bunn Jr, AstraZeneca, ImClone Systems, Eli Lilly, GlaxoSmithKline, Amgen, Genentech, sanofi-aventis, Boehringer Ingelheim, Bristol-Myers Squibb, OSI Pharmaceuticals, Roche; Joe B. Putnam Jr, Bristol-Myers Squibb; David Gandara, Genentech, Bristol-Myers Squibb Research Funding: David Gandara, Bristol-Myers Squibb, Eli Lilly, Pfizer Expert Testimony: None Other Remuneration: None

\section{AUTHOR CONTRIBUTIONS}

Conception and design: Katherine M.W. Pisters, John J. Crowley, Wilbur A. Franklin, Paul A. Bunn Jr, Robert J. Ginsberg, David Gandara Administrative support: Eric Vallières, Wilbur A. Franklin Provision of study materials or patients: Katherine M.W. Pisters, Eric Vallières, Paul A. Bunn Jr, Joe B. Putnam Jr, David Gandara Collection and assembly of data: Katherine M.W. Pisters, Eric Vallières, John J. Crowley, Wilbur A. Franklin, Paul A. Bunn Jr, Kari Chansky Data analysis and interpretation: Katherine M.W. Pisters, Eric Vallières, John J. Crowley, Paul A. Bunn Jr, Kari Chansky

Manuscript writing: Katherine M.W. Pisters, Eric Vallières, John J. Crowley, Paul A. Bunn Jr, Kari Chansky, David Gandara

Final approval of manuscript: Katherine M.W. Pisters, Eric Vallières, John J. Crowley, Wilbur A. Franklin, Paul A. Bunn Jr, Joe B. Putnam Jr, Kari Chansky, David Gandara

\section{REFERENCES}

1. Roth J, Fossella F, Komaki R, et al: A randomized trial comparing perioperative chemotherapy and surgery with surgery alone in resectable stage IIIA non-small cell lung cancer. J Natl Cancer Inst 86 673-680, 1994

2. Roth J, Atkinson E, Fossella F, et al: Long term follow-up of patients enrolled in a randomized trial comparing perioperative chemotherapy and sur- gery with surgery alone in resectable stage IIIA nonsmall cell lung cancer. Lung Cancer 21:1-6, 1998

3. Rosell R, Gomez-Codina J, Camps C, et al: A randomized trial comparing preoperative chemotherapy plus surgery with surgery alone in patients with non-small cell lung cancer. N Engl J Med 330:153158, 1994

4. Rosell R, Gomez-Codina J, Camps C, et al: Preresectional chemotherapy in stage IIIA non-small cell lung cancer: A 7-year assessment of a randomized controlled trial. Lung Cancer 47:7-14, 1999
5. Dillman R, Seagren S, Herndon J, et al: Improved survival in stage III non-small cell lung cancer: Seven-year follow-up of CALGB 8433. J Natl Cancer Inst 88:1210-1215, 1996

6. Sause WT, Scott C, Taylor S, et al: Radiation Therapy Oncology Group 88-08 and Eastern Cooperative Oncology Group 4588: Preliminary results of a phase III trial of regionally advanced, unresectable non-small cell lung cancer. J Natl Cancer Inst 87:198-205, 1995

7. Pisters KM, Ginsberg RJ, Giroux DJ, et al: Induction chemotherapy before surgery for early-stage 
lung cancer: A novel approach: Bimodality Lung Oncology Team. J Thorac Cardiovasc Surg 119:429-439, 2000

8. Reference deleted

9. Therasse P, Arbuck SG, Eisenhauer EA, et al: New guidelines to evaluate the response to treatment in solid tumors. J Natl Cancer Inst 92:205-216, 2000

10. The International Adjuvant Lung Cancer Trial Collaborative Group: Cisplatin-based adjuvant chemotherapy in patients with completely resected nonsmall cell lung cancer. N Engl J Med 350:351-360, 2004

11. Winton $T$, Livingston $R$, Johnson $D$, et al: Vinorelbine plus cisplatin vs. observation in resected non-small cell lung cancer. N Engl J Med 353:25892597, 2005

12. Strauss GM, Herndon J, Maddaus MA, et al: Randomized clinical trial of adjuvant chemotherapy with paclitaxel and carboplatin following resection in stage IB non-small cell lung cancer (NSCLC): Report of Cancer and Leukemia Group B (CALGB) Protocol 9633. 22:621s, 2004 (suppl; abstr 7019)

13. Douillard J, Rosell R, De Lena M, et al: Adjuvant vinorelbine plus cisplatin versus observation in patients with completely resected stage IB-IIIA nonsmall cell lung cancer (Adjuvant Navelbine International Trialist Association [ANITA]): A randomized controlled trial. Lancet Oncol 7:719-727, 2006

14. Pignon J, Tribodet $H$, Scagliotti GV, et al: A pooled analysis of five randomized clinical trials including 4,584 patients. J Clin Oncol 24:366s, 2006 (suppl; abstr 7008)
15. Depierre A, Milleron B, Moro-Sibilot D, et al: Preoperative chemotherapy followed by surgery compared with primary surgery in resectable stage I (except T1N0), II, and IIIA non-small cell lung cancer. $\mathrm{J}$ Clin Oncol 20:247-253, 2001

16. Depierre A, Westeel V, Milleron B, et al: 5 year results of the French randomized study comparing preoperative chemotherapy followed by surgery and primary surgery in resectable stage I (except T1N0), II and IIIA non-small cell lung cancer. Lung Cancer 41:S62, 2003 (suppl 2; abstr O-211)

17. Sorensen JB, Riska H, Ravn J, et al: Scandinavian phase III trial of neoadjuvant chemotherapy in NSCLC stages IB-IIIA/T3. J Clin Oncol 24:400s, 2006 (suppl; abstr 7146)

18. Gilligan D, Nicolson M, Smith I, et al: Preoperative chemotherapy in patients with resectable non-small cell lung cancer: Results of the MRC LU22/NVALT/EORTC 08012 multicentre randomized trial and update of systematic review. Lancet 369:1929-1937, 2007

19. Scagliotti GV, Pastorino U, Vansteenkiste JF, et al: A phase III randomized study of surgery alone or surgery plus preoperative gemcitabine-cisplatin in early-stage non-small cell lung cancer (NSCLC): Follow-up data of ChEST. J Clin Oncol 26:399s, 2008 (suppl; abstr 7508)

20. Felip E, Massuli B, Alonso G, et al: Surgery alone, preoperative paclitaxel/carboplatin chemotherapy followed by surgery, or surgery followed by adjuvant paclitaxel/carboplatin chemotherapy in early stage non-small cell lung cancer: Results of the
NATCH multicentre randomized, phase III trial. J Clin Oncol 27:382s, 2009 (suppl; abstr 7500)

21. Berghmans $T$, Paesmans $M$, Meert $A$, et al: Survival improvement in resectable non-small cell lung cancer with (neo)adjuvant chemotherapy: Results of a meta-analysis of the literature. Lung Cancer 49:13-23, 2005

22. Burdett $S$, Stewart L, Rydzewska L: A systematic review and meta-analysis of the literature: Chemotherapy and surgery versus surgery alone in non-small cell lung cancer. J Thorac Oncol 1:611621, 2006

23. Piedbois $P$, Buyse $M$ : Meta-analyses based on abstracted data: A step in the right direction, but only a first step. J Clin Oncol 22:3839-3840, 2004

24. Lim E, Harris G, Patel A, et al: Preoperative versus postoperative chemotherapy in patients with resectable non-small cell lung cancer: Systematic review and indirect comparison meta-analysis of randomized trials. J Clin Oncol 26:408s, 2008 (suppl; abstr 7546)

25. Martin J, Ginsberg R, Abolhoda A, et al: Morbidity and mortality after neoadjuvant therapy for lung cancer: The risks of right pneumonectomy. Ann Thorac Surg 72:1149-1154, 2001

26. Rusch V, Albain K, Turrisi A, et al: Phase III trial of concurrent chemotherapy and radiotherapy (CT/ $\mathrm{RT}$ ) versus CT/RT followed by surgical resection for stage IIIA-N2 non-small cell lung cancer: Outcomes and implications for surgical management in North American Intergroup 0139 (RTOG 9309). Lung Cancer 49:S15, 2005 (suppl 2; abstr O-035)

\section{Journal of Oncology Practice Now Available on PubMed Central}

Beginning with the January 2010 issue, full text for all JOP articles will be available on the NIH PubMed Central archive 4 months after publication. Once available, content is then delivered to PubMed, a metadata repository overseen by the National Library of Medicine and used by many scientific, technical, and medical researchers, making JOP material discoverable in PubMed for the first time.

Find yourself in PubMed. Submit your manuscript to JOP at jopsubmissions@ asco.org. 